\title{
GRAFFITI AS A FORM OF RHETORIC
}

\author{
Yelena Yerznkyan* \\ Grisha Gasparyan $^{* *}$ \\ Yerevan State University
}

The article touches upon graffiti discourse as a form of rhetorical speech and tries to analyse it according to the three strategies of persuasion suggested by Aristotle: ethos, pathos and logos. The article reveals how specific the graffiti discourse is in terms of using these strategies and how the latter make the speech more powerful and persuasive. Also, an attempt is made to reveal the role of metaphor in the performance of the strategy of pathos in graffiti discourse.

Keywords: graffiti, graffiti discourse, rhetoric, logos, ethos, pathos, metaphor.

\section{Introduction}

Graffiti is generally considered to be a social, cultural, political as well as a textual practice. It is a unique platform, where the speakers are unconstrained to express their ideologies, personal or social problems (Abel \& Buckley, 1977). Unlike other platforms, graffiti provides space practically for each member of the society and as a form of communication is being processed by a great number of people (Rodriguez \& Clair, 2009; Blanché, 2015; Nwoye, 1993).

It stands to reason that viewing graffiti as a piece of text on a public surface can be considered as a specific type of rhetorical speech. One can never be fully aware of the reasons behind the creation of a piece of graffiti unless s/he is its creator, but one thing that can logically be concluded is that graffiti texts have a well-defined purpose of persuading the reader to reconsider his opinion or the owned information concerning different issues. That is why in order to fulfill the task of a comprehensive study of graffiti

\footnotetext{
*yerznkyan@ysu.am

** grisha.gasparyan96@gmail.com

This work is licensed under a Creative Commons

Attribution-NonCommercial 4.0 International License.
}

Received: 20.01.2021

Revised: 28.04 .2021

Accepted: 22.05.2021

(C) The Author(s) 2021 
discourse we are analyzing it as a form of rhetorical speech based on the three components suggested by Aristotle (also known as the persuasion triad). By taking this angle for the analysis we can reveal many persuasive and communicative functions performed by different figures of speech, most importantly the metaphor, which finds its expression in the visual and textual forms in graffiti discourse.

Before proceeding with the analysis proper we'll introduce the definition of the word rhetoric. Merriam-Webster Dictionary defines it both as a "skill in the effective use of speech", "a type or mode of language or speech", and as an "insincere or grandiloquent language" ("Rhetoric," n.d.-a).

Oxford Learner's Dictionary also underlines the possible "insincerity" of the rhetorical speech defining it as "speech or writing that is intended to influence people, but that is not completely honest or sincere" ("Rhetoric", n.d.-b).

The American Heritage Dictionary additionally stresses the particularity of the discourse rhetoric is used in: "A style of speaking or writing, especially the language of a particular subject" ("Rhetoric", n.d.-c).

We can do no more than to note that the understanding of these definitions is vital if we view graffiti discourse as a form of rhetorical speech. The first characteristic that makes the speech through graffiti different from the others (e.g. political rhetoric) is that of sincerity. Graffiti is quite a sincere discourse. Here the artists voicing their ideas are honest, truthful and courageous in terms of expressing their thoughts, attitudes and feelings. Finally, graffiti is a platform that provides space for those who do not want to be "sincere in front of the public".

\section{Aristotle's persuasion triad}

There are three well-known strategies suggested by Aristotle that are being implemented in a speech in order to make it more persuasive for the listeners/readers. These strategies include ethos, pathos and logos (Aristotel', 2018). All the facts are in favour of the belief that the implementation of these three strategies in speech is realized through the skilful use of a number of linguistic tools in order to attain the persuasive goals (Suciati, Ambriani, 2018). Ethos is the strategy with the help of which the author proves his credibility and shows how trustworthy his/her words 
are. Logos is the strategy in a persuasive speech that is responsible for the logical arrangement of the elements of a speech: whether the speech is convincing in terms of the facts or information presented in it. The third strategy to make the speech more persuasive is pathos. By the appropriate use of this strategy the author may appeal to the audience's emotions and evoke strong feelings.

It seems essential to stress out that graffiti is a type of discourse, the aim of which is more than simply to inform the audience, but also to persuade them in the ideologies expressed in it. Analysing the linguistic organization of the textual form of graffiti as well as viewing it from multimodal communication perspective, we can surely state that graffiti is a form of persuasive speech. Therefore, the three strategies that make the speech more credible, hence persuasive for the audience are subjected to an analysis based on the examples of pieces of graffiti discourse. The starting point we proceed from is the three-element model after which the speech is being created. These are the orator himself, the object he is speaking about and the audience he addresses his speech to (Aristotel', 2018, p. 35-36).

The speaker

The object

The audience

This model clearly reflects the linear sequence of actors through which the communication takes place. The main tool to realize this process is the language that creates the text and transfers it to the target audience.

\section{The performance of the strategies of persuasion in graffiti texts}

A very important point to be made is that the three strategies of persuasion in graffiti discourse are firstly performed with pure linguistic means, but as graffiti is a multimodal discourse, they can also be performed with a combination of textual-pictorial or textual-contextual resources.

The strategy of logos is mainly being manifested in graffiti discourse through the following means: a) conditional sentences, b) repetitions and oppositions, c) text-picture and physical context (reality).

Consider some pieces of graffiti to clarify these points:

"You can kill the protestor, you can't kill the protest, you can murder the rebel, you can't murder the rebellion". (KK Pires ${ }^{\mathrm{TM}}$ Goods, n.d.) 
There is some evidence to suggest that this example can be considered as a combination of conditional sentences, where the conditionality is expressed implicitly ([even if] you can kill the protestor, you can't..., [even if] you can murder the rebel, you can't...). The logic of the utterance and its persuasive goal are realized through the repetition of structurally similar sentences four times across the utterance. Additionally, the words kill and murder though used here to denote one and the same thing - "cause the death of a person or thing" - diversify the vocabulary of the utterance, intensify the statement made and can be viewed as a strategy of persuading the audience by using proper vocabulary and grammar. The use of derivational pairs (protestor-protest, rebel-rebellion) also help to achieve the desired goal.

Below is another example illustrating how the category of conditionality develops the logic of the utterance:

"When you can't control what is happening, challenge yourself to control the way you respond to what's happening. That's where the power is". ("When you can't', n.d.)

Here we also observe some sequences of "events" conveyed through a repetition of the actions and actors in the first sentence of the text under study (you, can/can't control, what is happening).

The conceptual center of the utterance is the phrase challenge yourself expressed with a verb in the imperative mood, which directs the main message towards the addressee. The strategy of logos is also indicated in the second sentence of the graffiti text. The sentence 'That's where the power is' sums up and completes the main message with the "key word" power, which can be considered as the second conceptual center of the utterance. One more minute detail that helps to realize the strategy of logos is the use of simple and continuous tense forms. The continuous tense form (what's happening) is used to create a certain situation, while the use of the simple tense form (you respond) is meant to bring more logic to the utterance implying the way the addressee should change his attitude towards "what is happening". 
As was mentioned above, the strategy of logos finds its expression in graffiti discourse through textualpictorial components, as well as through texts and the physical contexts they appear in (the immediate environment). Thus, in the following piece of graffiti (Pic. 1) the author tried to express his ideas using not only the text but also the surrounding environment of the graffiti: the text is in "close cooperation" with the surface it is

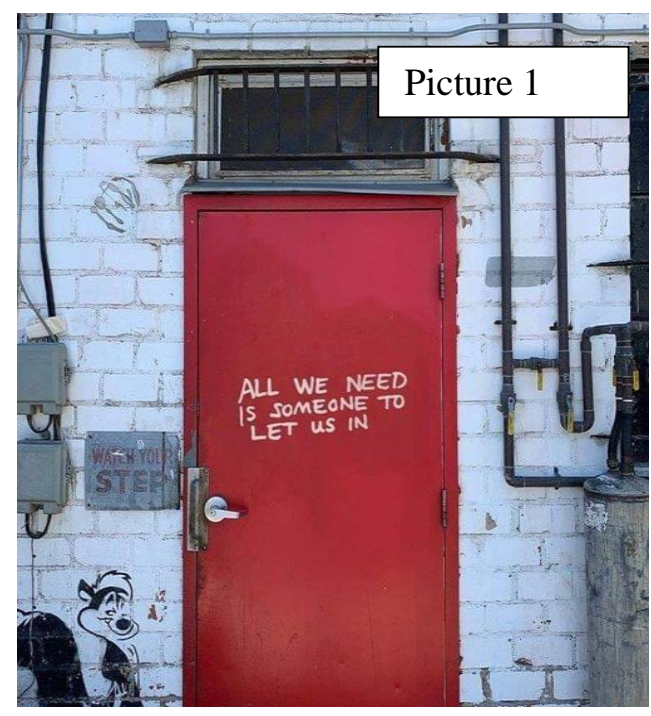
written on. The red door here is not just a surface, it is a part of the narration of the whole graffiti. The "persuasiveness" of the utterance is also conveyed via textual category of integrity. It is expressed with the pronouns we and us (inclusive we). They make the speech more intimate and addressee-friendly.

Below we'll observe how text integrity can establish another mode of persuasion - the ethos. The use of the textual category of integrity here is slightly different: if the strategy of logos uses the textual category of integrity to make the speech more intimate and friendly, when used to perform the strategy of ethos it is meant to make the speech more credible and impactful.

Besides the category of integrity, the ethos can be also performed in graffiti discourse through intertextuality with famous narratives and direct citations of famous quotes and sayings.

Before we go any further with the analysis of the examples, we would like to dwell on a piece of graffiti that shows unveiled sarcasm for the graffitists who are used to citing famous people to make their speech more credible, in other words, to make use of the ethos either intentionally or unintentionally. 
This piece of graffiti (Pic.

2) obviously expresses irony. The irony is achieved through negation of what has been said by adding the name of the "author" (Plato) at the end of the text. The creator of the graffiti considers it reasonable

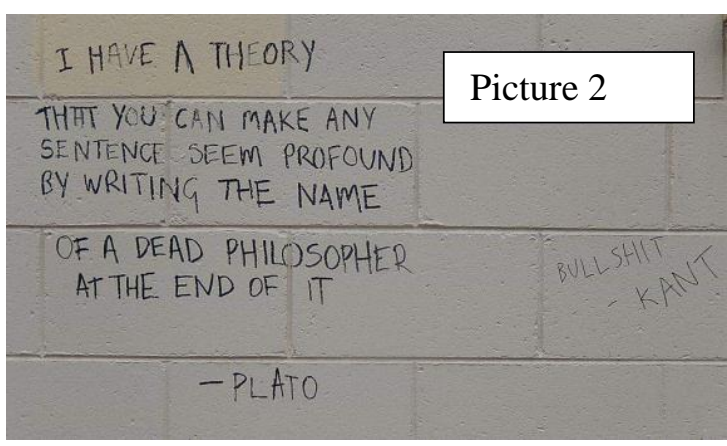
to use a reputable source as he wants to make his speech more powerful and persuasive. In other words, the persuasiveness of a speech heavily depends on the proper use of the ethos, which in this case is conveyed through the adjective "dead", that endows the message both with irony and trustworthiness. As we can judge from what is written in the lower righthand corner of the graffiti, it triggers more communication across the context it appeared in and constitutes a logical continuation of the main message.

As was mentioned above, the strategy of ethos in graffiti discourse can be established by adequate use of the textual category of integrity, that is seen to perform the strategy implicitly. In order to "obtain" the credibility of the information stated, the author directs his message to the audience involving himself as one of the heroes of the events. This way he authorizes his speech by implying that whatever he says is worth believing in, since it might be based on his personal life experience, on his deeds and misdeeds, his achievements and failures. To make this point more comprehensible consider the following example:

\footnotetext{
"This town is full of LOSERS. You're one, I'm one, she's one”. (Lucy Grace, n.d.)
}

In this case ethos is conveyed through the pronoun $I$ as one of the main heroes of the event. This component of ethos is inserted into the utterance with the sandwich effect: the "elaboration" of the statement (The town is full of losers) begins with the pronoun indicating the addressee (you), while in the middle the author mentions himself not only to weaken the potential intense feelings of the addressee, but also to make his statement more persuasive. 
Graffiti discourse is a "limited" one - both in terms of time (the creators most of the time must be quick for the sake of anonymity) and in terms of the physical space in which they create their work. That is why the author of the graffiti uses the shortened conjugation forms of the verb "to be", thus economizing the language of his speech. The key element of the utterance (the word LOSERS) is all capitalized to highlight the aim of the utterance and to make the audience believe the statement made.

In graffiti discourse the persuasive strategy of ethos is utilized through allusions based on intertextual relations with famous narratives. Generally speaking graffiti discourse contains quotes intertextually bound with many different narratives - ranging from the Bible to modern pieces of writing.

Consider the following example (Pic. 3).

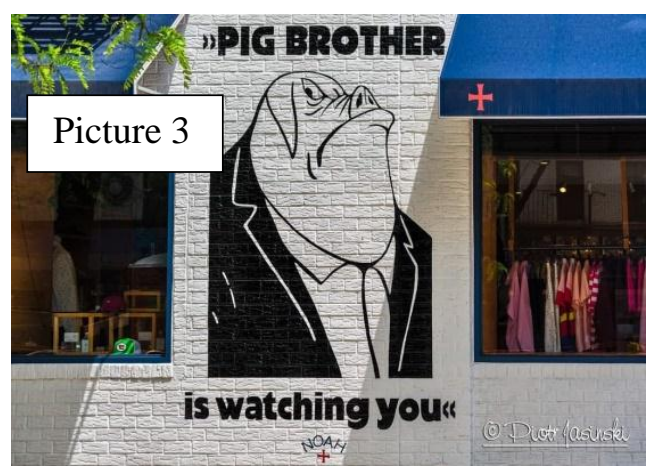

This piece of graffiti (Pig brother is watching you) is rather peculiar in terms of the intertextual narratives it alludes to. To begin with it should be mentioned that here the grafiti creator refers to the two famous novels by George Orwell - "Animal Farm" and "1984". In other words, the author tries to use Orwell and his writings as a tool to make his speech more credible, hence persuasive. The utterance is a hybrid of the two narratives: on the one hand, the graffiti contains the narrative of being supervised by some authorities (watching you), on the other hand, the same authorities are compared with an animal - pig. This rather harsh comparison is being "enriched" and made more "colourful" with the accompanying image of the animal that looks straight at the addressee and is clothed and positioned like a human being, that is to say like a "big brother". Note that the words pig and big are used as puns.

Consider another example:

This piece of graffiti (Pic. 4) begins with the name of the book it has intertextual relations with -1984. Obviously, this is done in order to

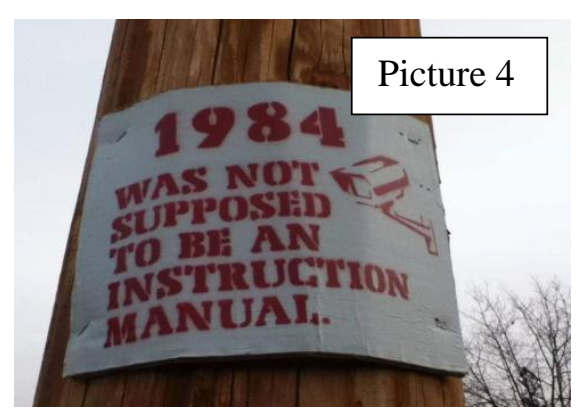


intensify the ethical appeal (to convince the audience). The accompanying pictorial material performs two functions:

- To make a connection between the present (surveillance with cameras) and the past (the novel by G. Orwell "1984").

- To clarify which part of the novel the author intends to point out: the famous lines "Big brother is watching you" with whatever sign or symbol it may cover when used as an "instruction manual".

Graffiti discourse may also have pieces of rhetorical speech that contain direct citations of famous sayings and quotes with the name of the author mentioned.

It is interesting to note that citations in graffiti discourse should be concrete so that the ongoing social and political situations can be figured out and projected on.

Here are some examples to illustrate what has been discussed above:

"Never think that war, no matter how necessary, nor how justified, is not a crime”- E. Hemingway. (Emily Logan, n.d.)

"Art is anything you can get away with" - Andy Warhol. (St Christine, n.d.)

"One original thought is worth a thousand mindless quotings" - Diogenes. (Steven Pentaris, n.d.)

Graffiti discourse also realizes the strategy of ethos by tagging the names of the creators (authors) of graffiti. In order to clarify this point, let us adduce some examples:

"Sometimes being the only one that isn't desperate to be noticed is what makes them pay attention" - Morley. ("Sometimes being", n.d.)

"A lot of parents will do anything for their kids, except let them be themselves" - Banksy. (Jennifer Sinclair, n.d.) 
"If you fear failure, you're already considering it an option”-WRDSMTH. (Su Ring, n.d.)

The quotes from graffiti discourse speak about two main things:

1. The strategy of ethos is being conveyed not only through intertextual narratives, but also by citing some lines of notable, well-known figures in the field, popular celebrities, etc. and referring to sources.

2. The graffiti culture is progressively becoming so widespread that creators want to keep the "copyright" rules and make their sayings more credible and persuasive.

The strategy of pathos in graffiti discourse is being utilized through a number of linguo-stylistic devices, metaphor being the most prominent of them.

To analyze metaphors in graffiti discourse we are guided by a stepwise procedure suggested by G. Stampoulidis and M. Bolognesi (2019). According to this procedure the topic of the piece of graffiti should be identified first. Next, the authors suggest that the analysis be carried out in three main dimensions, those being expression, conceptualization, communication. The dimension of expression implies that the researcher is supposed to find the verbal/pictorial elements that disharmonize with the topic of the whole graffiti. The dimension of conceptualization presupposes that the researcher finds out what kind of abstract concept the metaphor stands for. The dimension of communication reveals how metaphor fosters the communicative function of the utterance (Stampoulidis \& Bolognesi, 2019).

So, on the textual level, pathos is established by the adequate use of metaphors to make the speech more interesting and appealing to the audience by creating an emotional response to what is written in the text, thus eliciting different (positive or negative) feelings among the audience as well as to imply certain messages to avoid expressing them directly and stimulating thought and further actions.

Below are several examples to illustrate the points mentioned above:

"Atheism is a non-prophet organization".

(sarahinbrunswick, n.d.) 
The topic of this piece of graffiti is surely religion. The metaphoric transference of meaning is based on the comparison of atheism as an organization and not a worldview or disbelief. It is presented as an organization firstly to make use of a pun based on the homophonic relation between the expressions non-prophet - non-profit, secondly, to imply the characteristics "atheism" may share with a non-profit organization: they are both free and are made to serve for collective benefit. Considering the dimension of communication we can say that the utterance is meant to express sarcasm towards religiousness and promote atheism as an organization everyone can "benefit from".

As is known, metaphors are generally used to imply messages, instead of telling them straightforwardly. Graffiti, though is a "sincere" discourse thanks to its anonymity, sometimes comprises pieces of texts using metaphors that are meant to imply messages, rather than to convey them explicitly. Consider the following example:

"Only dead fish swim with the stream". (Kaleidoscopes And Polka Dots, n.d.)

The topic of this graffiti is most probably social. The metaphoric transference is based on the expression dead fish, which stands for the people who don't have their own opinion, do not think critically and rely on the public opinion. The stream here may stand for the dominant public ideologies that can control people and change their way of thinking.

In the dimension of conceptualization this piece of graffiti implies some kind of advice for the readers not to follow the masses but to keep analysing the current issues and to shape personal viewpoints. The adverb only being in the initial position intensifies the statement and doubles the impact of the communicative aim of the utterance: to interact with the society, advise its members to think critically and question established "wisdom".

Graffiti, being a multimodal discourse, makes use of not only verbal but also semiotic and visual metaphors to sound more impactful and imply certain messages. The following graffiti is a combination of linguistic and semiotic means: 
"If they constantly leave you feeling '??????!!???' that's not the one". (Shigeka, n.d.)

The topic of this piece of graffiti text most probably is strictly personal. The metaphoric nature of the utterance is largely conditioned by the following punctuation marks: '?' and '!'. We can "decode" the metaphor here, if we correlate these marks with the word "feeling". The question mark, in fact, stands for the feeling of suspicion, whereas the exclamation mark - to indicate strong feelings and emphasize the statement. The sequence of exclamation marks is being interrupted with question marks again, in this position it indicates instability in terms of feelings. In the process of conceptualization the metaphor works as a tool for building confidence for the main heroes of the event (they), thus fostering the communicative aim of the graffiti - advising the audience.

Interesting to note that in graffiti discourse metaphors are not only used to imply the communicative aim of the utterance, but also play an essential role in creating oppositions with the transference of meaning. Consider the following example:

"We worship an invisible god and slaughter a visible nature, without realizing that this nature we slaughter is the invisible god we worship". (bjornjohansen, 2018)

The topic of this piece of graffiti is ecology. The metaphor is constructed here with conceptual oppositions invisible-visible, god-nature, slaughter-worship. The words slaughter and worship constitute the metaphoric center of the utterance and at the same time the ends of the binary opposition that shape the main message of the utterance. The phrase without realizing consitutes the conceptual center of the utterance and combines the two metaphoric centers with the ends of the binary opposition.

As for the communicative dimension, this piece of graffiti is first meant to express complaint, secondly, to advise the readers. This aim is achieved implicitly both through metaphor, as well as through the above-mentioned conceptual center of the utterance.

The following graffiti (Pic. 5) presents a combination of visual and verbal metaphors. The topic of the graffiti is social. The metaphoric 
transference is based on both visual and verbal similarity of the word mouse - as a rodent and as a gadget.

Taken roughly, this piece of graffiti is more like a fable in a visual form, its "didactic" part is the implication conveyed by the content of the whole graffiti. The graffiti can be projected on various

Picture 5

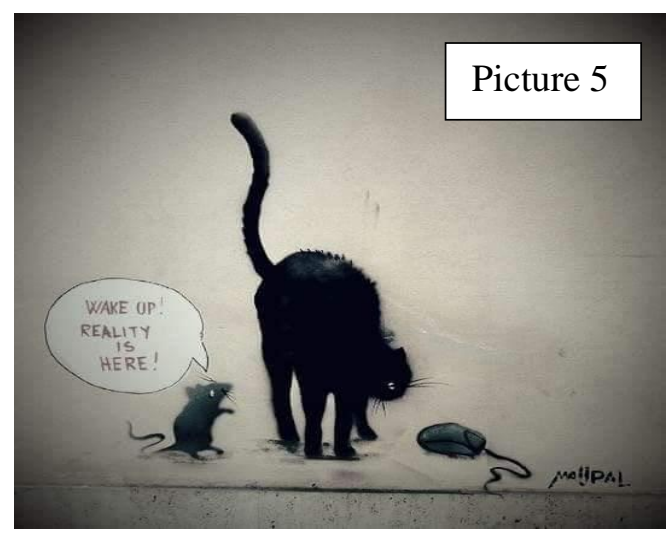
social situations, but most probably it implies a call to the people to "wake up" from the virtual-parallel reality and "to start living in the real world". The latter constitutes the communicative aim of the whole graffiti and should be considered carefully by the audience.

\section{Conclusion}

Having described graffiti as a form of rhetorical speech we can conclude that the three strategies of persuasion suggested by Aristotle have their unique linguistic manifestation in graffiti discourse, first of all determined by different semantically interconnected modes of communication.

The application of these strategies in graffiti discourse manifests itself in a multitude of ways. Graffiti creators convey them first and foremost through appropriate use of various linguistic (vocabulary, grammar, style, textual categories, intertextuality etc.), as well as non-linguistic (picture, physical environment etc.) means aiming at convincing and persuading the audience with reason (thus appealing to logic), via the authority and the credibility of the "persuader" (appealing to ethics) and by "hooking" the audience with feelings and emotions, evoking an emotional response (i.e., appealing to emotions). Metaphor in graffiti discourse is used to perform the persuasive strategy of pathos, to make the speech more impactful on the emotions of the audience and most importantly to achieve the communicative aim of the utterance implicitly. 


\section{References}

Aristotel'. (2018). Ritorika. [Rhetoric]. (Perevod s drevnegrecheskogo M. Platonovoř), Moskva, Izdatel'stvo «E்».

Abel, E., \& Buckley, B. (1977). The handwriting on the wall: Toward a sociology and psychology of graffiti. Westport, CT: Greenwood.

Blanché, U. (2015). Street art and related terms - discussion and working definition. SAUC - Journal, 2 (1), 6-18. https://doi.org/10.25765/sauc.v1i1.14.

Nwoye, O. (1993). Social issues on walls: Graffiti in university lavatories. Discourse and Society, 4 (4), 419-442. New Delhi: SAGE. Retrieved from https://www.jstor.org/stable/42888781

Rodriguez, A., \& Clair, R., P. (2009). Graffiti as communication: Exploring the discursive tensions of anonymous texts. Southern Communication Journal, 65 (1), 1-15. https://doi.org/10.1080/10417949909373152.

Stampoulidis, G., \& Bolognesi, M. (2019). Bringing metaphors back to the streets: A corpus-based study for the identification and interpretation of rhetorical figures in street art. Visual Communication, O(0), 1-35. https://doi.org/10.1177/1470357219877538.

Suciati, S., \& Ambarini, R. A. (2018). Rhetorical analysis of selected speeches of Indonesian woman politicians: Pre-electoral strategies. Journal of Computational and Theoretical Nanoscience, 24 (6), 45414545. https://doi.org/10.1166/asl.2018.11650 .

\section{Dictionaries}

Rhetoric. (n.d.-a) In Merriam-Webster Dictionary. Retrieved from merriamwebster.com

Rhetoric. (n.d-b.) In Oxford Learner's Dictionary. Retrieved from oxfordlearnersdictionaries.com

Rhetoric. (n.d-c) In American Heritage Dictionary. Retrieved from ahdictionary.com

\section{Sources of Data}

Bjornjohansen. (2018, 25 June). We worship an invisible god and slaughter a visible nature, without realizing that this nature we slaughter is the 
invisible god we worship. Retrieved from https://twitter.com/bjornjohansen/status/1011325818700693505

Emily Logan. (n.d.). Graffiti quote!,. Retrieved from https://www.pinterest.com/pin/70157706669162582

Jennifer Sinclair, (n.d.). A lot of parents will do anything for their kids..." Banksy [595x407] [OC]. Retrieved from https://www.pinterest.com/pin/235594624235974486/

Kaleidoscopes And Polka Dots. (n.d.). Never Forget That Only Dead Fish Swim with the Stream - Tiny...Retrieved from https://www.pinterest.com/pin/629237379159929039/

KK Pires ${ }^{\mathrm{TM}}$ Goods, Resist. Retrieved from https://www.pinterest.com/pin/93731235983819996

Lucy Grace.(n.d.) This town is full of LOSERS. You're one, I'm one, she's one. Retrieved from https://www.pinterest.com/pin/324962929347196816

sarahinbrunswick, (n.d.). Atheism. Retrieved from: https://www.flickriver.com/search/Atheism

Shigeka. (n.d.). If they constantly leave you feeling '??????!!???' that's not the one. Retrieved from https://www.pinterest.com/pin/859554278865588355

Sometimes being the only one that isn't desperate to be noticed is what makes them pay attention" - Morley. Retrieved from https://www.pinterest.nz/pin/734368282958938062/

St Christine. ( n.d.). art is anything you can get away with. Retrieved from https://www.pinterest.com/pin/2462974786294351

Steven Pentaris. (n.d.). One original thought is worth a thousand mindless quotings .... DIOGENES. Retrieved from https://www.pinterest.com/pin/83387030571106112

$\mathrm{Su}$ Ring. (n.d.). WRDSMTH -vs- CITIZEN X. Retrieved from https://www.pinterest.com/pin/32651166037957985

When you can't control what is happening, challenge yourself to control the way you respond to what's happening. (n.d.). Retrieved from https://www.pinterest.com/pin/260223684706868160 


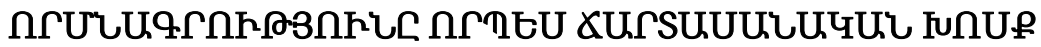

\section{Gltium Enqulujuí qph2u quuuqupjuis}

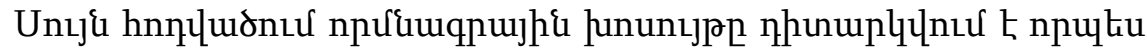

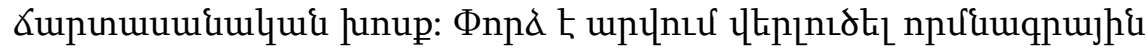

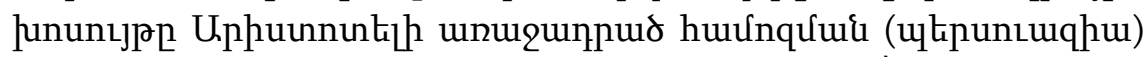

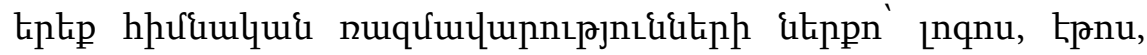

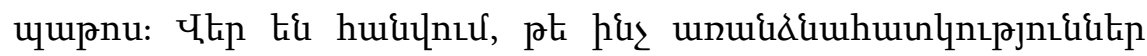

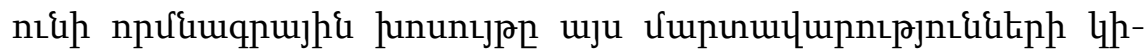

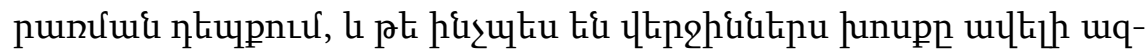

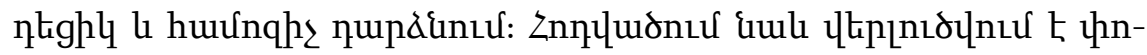

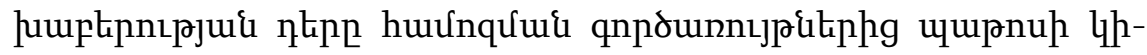

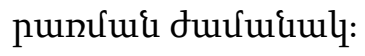

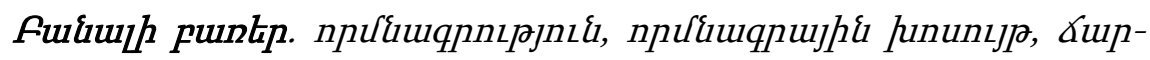

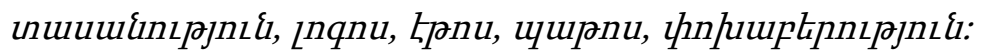

